\title{
The Teachers' Experiences with Video Games play in Saudi Arabia
}

\author{
Mohammed A. Alqurashi", and Mia K. Williams.
}

\begin{abstract}
The purpose of this quantitative study was to investigate Saudi teachers' experiences with video gaming. This study described the current condition of video game usage and the reasons that attract teachers to play video games and their preferable games types. Also, it showed the different between gender (male, female), and teachers' experiences in teaching (1-5, 6-10, 11-15, 16-20, more than 20 years), and level of teaching (Elementary school, Middle school, and High school) and teachers region (North, South, West, East, Middle). There were 930 teachers from Saudi Arabia who participated in this study. In general the Saudi teachers' spent in average about 84 minutes per week playing video games. The findings revealed $53.3 \%$ of total participants did not play video games and $46.7 \%$ of participants played video games about three hours a week as average. The results showed that the most popular reason for playing video games among the participants was for enjoyment. Although Puzzles games were the most popular type of games for female participants, the most popular type of games for male participants was sports. Also, the results showed that male teachers reported more hours playing video games than female teachers and teachers who had 6-10 years of experience reported highest number of hours playing video games. On the other hand, the results showed that there were no different among levels of teaching (elementary school, middle school, and high school) and teachers' regions (North, South, West, East, Middle) in the number of hours spent per week on video game play.
\end{abstract}

\section{Keywords - Saudi Arabia, Teacher, Video Games.}

\section{INTRODUCTION}

In recent years, technology has impacted the daily lives of humans and now plays a significant role for our futures [29]. Games are one of the important technologies that affect children and adolescents. Today, the impact of video games on the youth is similar to that of religion, political movements, music, and culture [24]. They have become a primary entertainment tool for children and a very prominent part of our kids' leisure time [18]. Games are one of a few technological applications that have improved at a constant

\section{* Corresponding author}

Manuscript received October. 15, 2015. This research is a part of big project about "Saudi teachers' experiences and attitudes toward integrating video games for learning: affordances and constraints of using video games in Saudi Arabia classrooms

Dr. Alqurashi is working at Ministry of Education in Saudi Arabia. He graduated from Educational Technology Department, College of Education and Behavioral Sciences, University of Northern Colorado Greeley, CO.

Dr. Williams is Assistant Professor of Educational Technology and Social Foundations, College of Education and Behavioral Sciences, University of Northern Colorado Greeley, CO. and rapid speed [30]. Miller said in reference [24], "Outside the classroom, playing is one of the fundamental human activities, one of the first that human children develop together with talking, toddling, and relating to others" (p.3). Also, Miller mentioned in reference [24] that video games have become the center of attention in all homes today including all modes of digital applications such as PlayStation, GameCube, Sega, and Xbox. Therefore, the concept of gaming has transferred from being a form of entertainment to a form of technological literacy.

Although playing is a natural human activity such as communicating, eating, working, playing has different characteristics since it is often a spontaneous activity [24]. Reference [30] stated that playing games becomes a normal action like language.

Nowadays, about 155 million Americans play video games. In the United States, there is an average of two players in each family and about $80 \%$ of families own devices to play video games [11]. Since 1996, there has been a marked growth in the development of video games. Recently, the percentage of Internet expansion in Saudi Arabia has increased at a high rate; there are 19.6 million users, representing about $63.7 \%$ of Saudi Arabia's population compared to 5\% in 2001 [9].

Reference [11] showed there was a sharp increase in game titles from 2002 to 2011. In parallel, the gaming industry has increased; more than 135 million games were sold during 2014 , which provided about $\$ 22$ billion in revenue [11]. In Spain, the gaming industry recorded outstanding economic results in 2012 with 822 million games sold [21]. The size of spending of the Saudi child on electronic games and entertainment was $\$ 400$ a year [4].

Games are an innate activity for both humans and animals. This can clearly be seen when kids enjoy interacting and playing with others from childbirth. Reference [30] indicated that a game is a "free activity" known to be "not serious" and is not considered a part of formal life (p.470). Also, it is practiced in specific places and times. Games are "an anthropological constant" and we can say that the game is a counterpart to leisure [30]. Playing a game is dependent on elements that exist in the game such as rules, steps or levels, collaboration, competition, whether or not a player wins or loses, and fun [24].

All the above evidence is in agreement with many researchers' views that games can no longer be considered a minor part of our culture and our lives because games have become an essential element in many peoples' lives [6]. According to reference [10], gaming is gaining huge value in 
daily life and playing games has invaded everything in our lives.

Regarding learning, researchers have noted that games can fascinate learners and get their attention [8]-[21]. Yet, teachers in learning contexts have not embraced gaming concepts despite technology integration practices. In the 21st century, the issue of games in education is prominent, especially due to huge developments in the games industry [11]. The role of teachers is to provide quality education indicated by critical elements of the learning process [15]. Therefore, effective teachers utilize sound methods and active learning strategies including collaboration and use of games [15]. Some teachers may still not recognize the role of games in education; however, teachers need to be prepared to use games in education [24]. Games can be used in classrooms but to be effective, teachers need to be familiar with this technology. Therefore, this study aimed to identify if teachers in Saudi Arabia had any experiences with video game. Teachers' experiences with video game are very important and play a main role in the adoption and application of educational games in the classroom.

Games have a long history. Following the 15 th century when Europeans were playing chess, the military changed the chessboard to terrain maps in the 19th century [33]. War games have become the most famous and widely played games; they were very popular around World War II [33]. The scientific-technical and the information and telecommunications revolutions have played major roles in improving and developing games. These revolutions produced new types of games called electronic games or video games. Since 2009, interaction games have begun to compete in the gaming industry. Today, in 2016, anyone can carry a game system in their pocket with the wide spread use of the mobile smartphone [26].

There are many researchers studied the teachers experiences with games. Reference [17] conducted a pilot study about pre-service teachers' experiences with computer games and found more than $92 \%$ of participants played their first computer games in elementary or high school [17]. Furthermore, reference [16] conducted a study about attitudes toward digital gaming with 125 pre-service teachers. The researchers found most pre-service teachers played digital games [16].

Moreover reference [13] conducted a survey study with about 223 pre-service teachers about their attitude toward technology and using games in education. About 93 pre-service teachers currently played games. All of them played games before college. About 48 pre-service teachers (51.6\%) reported playing games before first grade. While $5.4 \%$ of participants were playing games for eight or more hours per week, $72 \%$ of participants were playing three or less hours per week [13].

Also, reference [38] conducted a study with 116 pre-service and in-service teachers about their current experience, attitudes, self- efficacy, and perceived challenges and barriers to the implementation of digital game-based learning (DGBL) in the classroom. He mentioned that most teachers played games lightly by using mobile devices [38].
Although boys and girls play games, there is a difference in their enjoyment. There is also a difference in the games used and playing style between the genders [24]. A number of studies showed there are differences between genders in learning, thinking, and playing [24]. Interestingly, according to many studies in the field, there is a significant difference between genders with regard to playing games. It has been observed that males are willing to play video games more often than females [13]-[24]. Reference [34] mentioned that computer are appeal to the male more than female because most the games have been related to math and science fields that show an overrepresentation of males. [34].

Many researchers discussed the reasons for playing games. Although, reference [20] presented four main reasons for playing games (motivation, fantasy, challenge, and curiosity), reference [5] believed there is one widespread reason that motivates players to play game--curiosity. According to [24], many motivational characteristics of games include competition, curiosity, and challenge. Moreover, video games should contain challenge elements because challenge is a strong motivator for students to play them [1]. In contrast, $85 \%$ of parents in the United States feel fun is the main reason their children are playing games [11]. Reference [3] found there are three underlying factors that attract middle school students to play video games in Saudi Arabia--competition, discovery, and knowledge. Reference [24] mentioned males seek to win or beat the video games rather than simply playing for enjoyment.

People do differ in their game preferences [19]-[2]-[24]. There are many types of video games: fighting games, puzzle games, sports games, adventure games, strategy games, etc. Some studies discovered most students prefer fighting games [32]. Reference [3] found male students preferred fighting games and sports games while female students preferred puzzle and adventure games. In general, males prefer fighting games because, as reference [24] mentioned, some characteristics present in fighting games use short-term memory and repeated actions. Males usually prefer the types of games that require strong qualities, such as fighting and sport games, while females prefer puzzle games [2]-[24].

Reference [23] conducted a survey study of English school children; they found playing games was the first activity choice for boys. In contrast, the girls played games when they felt bored. Similarly, in the same area, reference [31] conducted research on German secondary school children to examine game preferences with regard to performance and gender differences. The authors used three types of players: nonplayers, action and simulation game players, and logic and skill-training game players. More than $81 \%$ of males preferred the action and simulation play while more than $82 \%$ of females preferred logic and skill training game play [31].

The purpose of this quantitative study was to investigate teachers' experiences with gaming in Saudi Arabia. This study described the current condition of video game usage. In general, this study identifies whether or not the teachers in Saudi Arabia play video games and, if there is a high percentage of game players and playing hours, then the integration of games in middle school curriculum may be a 
useful teaching strategy.

The game in this study means video game. In Oxford English Dictionary, a video game is defined as "a game played by electronically manipulating images displayed on a television screen" [36].

\section{RESEARCH QUESTIONS}

This quantitative study was designed to answer seven research questions that are:

Q1) What are Saudi Arabia teachers' current gaming experiences as defined by the number of hours spent on video games per week?

Q2) What are the common reasons that attracted Saudi teachers to play video games?

Q3) Which type of video games are preferred by Saudi teachers?

Q4) Is there a significant difference between teachers' gender in the number of hours spent per week on video game play?

Q5) Is there a significant difference among teachers' level of teaching (elementary school, middle school, and high school) in the number of hours spent per week on video game play? Q6) Is there a significant difference among teachers' years of experience (1-5, 6-10, 11-15, 16-20, more than 20 years) in the number of hours spent per week on video game play?

Q7) Is there a significant difference among teachers' region (North, South, West, East, Middle) in the number of hours spent per week on video game play?

\section{METHOD}

There were 930 Saudi teachers completed the survey. The participants included educators who are teaching in Saudi Arabia. The ages of participants ranged from 22 to 60 years. Participant characteristics included Saudi Arabia teachers working for the Ministry of Education in public or private schools; taught in elementary, middle, and high schools; and taught in many different content areas [25]. According to the Ministry of Education in Saudi Arabia report in 2014, there are about 441,529 teachers--201,551 male teachers (45.6\%) versus 239,978 female teachers (54.4\%). According to the Ministry of Education in Saudi Arabia, there are five regions: the north, the south, the east, the west, and the middle. Each region has many education departments or districts [25].

Quantitative methods were employed in this study. The data was collected by questionnaire. The researcher used online questionnaire to investigate gaming usage. The questionnaire consisted of two sections. The first section requests demographic information and the teacher's background such as gender, level of teaching, years of experience in teaching, region, and playing experiences by the number hours teachers currently play video games per week on average. The second section contained questions about favorite video games and the reasons for playing the games. These sections are the first section of The Games in the Classroom Attitudes Survey (GCAS) developed by the researcher.

After the data were collected, the researcher conducted quantitative analyses. The obtained data were uploaded to
SPSS. First the researcher found the demographic information. Then descriptive methods such as frequency and means and standard deviations were used to answer the first three research questions. The rest of questions were analyzed by an ANOVA method because there was one dependent variable (the numbers of hours' video games are played) and many independent variables such as (gender, teachers' experiences in teaching, level of teaching, and region).

\section{RESULT}

There were 930 Saudis' teachers who completed the survey as participants in this study (see Table I). Male teachers totaled 447 and represented $48.1 \%$ of the participants while female teachers totaled 483 and represented $51.9 \%$ of the participants.

TABLE I: FREQUENCIES AND PERCENTAGES OF PARTICIPANT CHARACTERISTIC VARIABLES.

\begin{tabular}{llll}
\hline & Variables & Frequency & Percent \\
\hline Gender & Male & 447 & 48.1 \\
& Female & 483 & 51.9 \\
& & & \\
& North & 61 & 6.6 \\
Region of & South & 102 & 11.0 \\
Saudi Arabia & East & 30 & 3.2 \\
Residency & West & 602 & 64.7 \\
& Middle & 135 & 14.5 \\
& & & \\
Level of & & & \\
teaching & Elementary & 385 & 41.4 \\
& Middle & 239 & 25.7 \\
& High & 306 & 32.9 \\
& & & \\
Teachers' & & & \\
experience in & $1-5$ & 201 & 21.6 \\
teaching & $6-10$ & 225 & 24.2 \\
& $11-15$ & 138 & 14.8 \\
& $16-20$ & 165 & 17.8 \\
& More than 20 & 201 & 21.6 \\
\hline
\end{tabular}

For the first research question, the participants were asked about the number of hours they spent during the week playing video games. The mean for hours that spent per week was $(\mathrm{M}=0.9)$. Their responses showed 496 teachers $(53.3 \%)$ did not play video games at all. Teachers who spent one hour a week were $256(27.5 \%)$. Teachers who played two hours a week were $47(5.1 \%)$ while 41 teachers spent three hours a week (4.4\%) playing video games. Four hours a week were spent by 15 teachers who represented $1.6 \%$ and five hours were spent by 19 teachers who represented $2.0 \%$. Nine teachers $(1.0 \%)$ spent six hours a week plying video games and the same number of teachers spent seven hours a week. The rest of the teachers (4\%) mentioned they spent different numbers of hours--eight hours by eight teachers to 30 hours by four teachers as can clearly be seen in Table II.

For non-player teachers, there were 224 (45.2\%) male teachers and 272 female teachers $(54.8 \%)$. In the West region, there were $331(66.7 \%)$ non-player teachers and the Middle region had $76(15.3 \%)$ non-player teachers. While there were $51(10.3 \%)$ non-player teachers in the South region, there were $27(5.4 \%)$ in the North region. Finally, there were $11(2.3 \%)$ 
non-player teachers in the East region of Saudi Arabia. The highest percentage of non-player teachers taught in elementary schools $(216,43.5 \%)$ while the lowest percentage of non-player teachers taught in middle schools $(118,23.8 \%)$. High schools had $162(32.7 \%)$ non-player teachers. There were $103(20.8 \%)$ non-player teachers with 1-5 years of experience and 96 (19.4\%) non-player teachers with 6-10 years of experience. The lowest percentage was non-player teachers who had 11-15 years of experience $(76,15.3 \%)$. There were $89(17.9 \%)$ non-player teachers who had 16-20 years of experience. Non-player teachers who had more than 20 years of experience had the highest percentage $(132,26.6 \%)$.

TABLE II. NUMBER OF HOURS SPENT PLAYING VIDEO GAME DURING THE WEEK BY TEACHERS

\begin{tabular}{ccc}
\hline Hours spent & Frequency & Percent \\
\hline Not plying & 496 & $53.3 \%$ \\
1 & 256 & $27.5 \%$ \\
2 & 47 & $5.1 \%$ \\
3 & 41 & $4.4 \%$ \\
4 & 15 & $1.6 \%$ \\
5 & 19 & $2.0 \%$ \\
6 & 9 & $1.0 \%$ \\
7 & 9 & $1.0 \%$ \\
8 & 8 & $0.9 \%$ \\
9 & 1 & $0.1 \%$ \\
10 & 8 & $0.9 \%$ \\
12 & 1 & $0.1 \%$ \\
14 & 5 & $0.5 \%$ \\
15 & 5 & $0.5 \%$ \\
16 & 1 & $0.1 \%$ \\
17 & 1 & $0.1 \%$ \\
20 & 2 & $0.2 \%$ \\
21 & 1 & $0.1 \%$ \\
28 & 4 & $0.1 \%$ \\
30 & & $0.4 \%$ \\
\hline & 5 &
\end{tabular}

For the second research question, the survey asked the respondents to identify reasons that attracted them to play video games. Not all teachers could answer this question. Just 434 teachers $(46.7 \%)$ who played video games could answer this question.

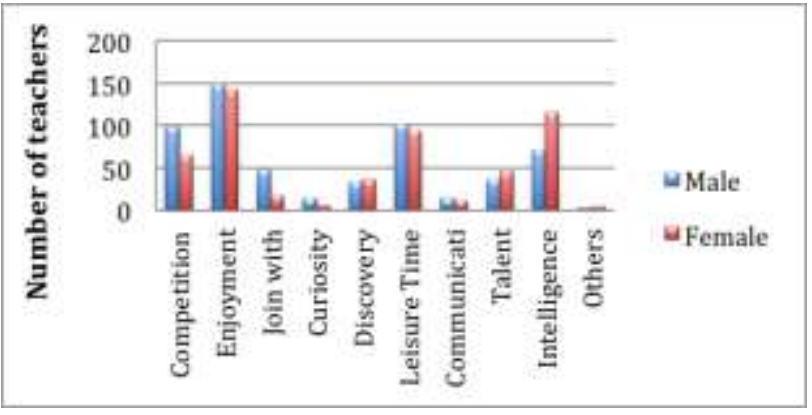

Fig. 1. Reasons for playing video games by gender.
As seen in Fig. 1, the most popular reason for playing video games among the participants was for enjoyment-- $66.8 \%$ of the total responses--with 148 for male and 142 for female. Playing for competition, which was $37.5 \%$ of the total participants, was higher for males--98 answers than for females--65 answers. On the other hand, 115 females played video games for intelligence development, while only 71 males played for the same reason. Playing video games for intelligence development represented $42.8 \%$ of the participants. Male and female participants were similar in playing video games for discovery (16.3\%) and for communication (5.7\%) reasons with 34 and 14 for males and 37 and 11 for females, respectively.

Only $15.2 \%$ of teachers played video games with others; 48 male and 18 female teachers chose this reason for playing. Playing video games for curiosity was chosen by 21 (4.8\%) of total participants (15 for male and 6 for female). A high percentage $(45.1 \%)$ of participants played video games to spend during leisure time-196 total answers where 102 of them were from males and 94 were from females. Playing video games to develop talent represented $18.9 \%$ of the total participants with 82 teachers (36 for male and 46 for female). Most participants who chose "Other" as the reason for playing video games represented $2.1 \%$ of the total responses; they mentioned that they played video games to share with their friends or spend some times with their kids and their families and relevant.

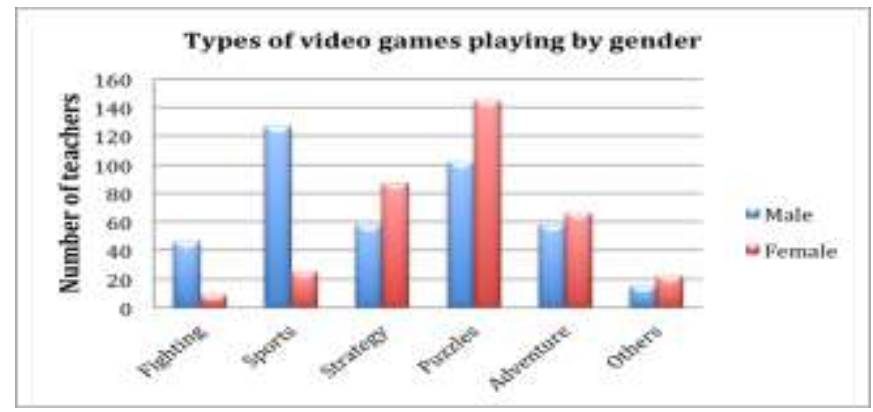

Fig. 2. The Number Of Respondents Playing Different Types Of Video Games By Their Gender.

For the third research question, the survey asked the participants about the type of video games they preferred see Fig .2. Only $434(46.7 \%)$ teachers who played video games answered this question. The highest percentage of teachers (56.9\%) chose the puzzle games as their prefer type of video games with 247 choices. Puzzles were the most popular type of games for female participants with 145 answers compared to 102 answers for male participants. On the other hand, the most popular type of games for male participants was sports with 127 answers but sports was a rare answer for females with only 25 responses. Sports video games represented $35.1 \%$ of 152 participants. While 46 male participants played fighting video games, which represented $12.7 \%$ of the total participants, only nine female participants did. The least chosen type of video games was fighting with only 55 participants. Males and females were similar in playing adventure video games with 58 and 66 answers, respectively. Adventure video games represented $28.5 \%$ of teachers who played video games with 124 choices. Female participants played strategy video games 
(87 answers) more than male participants (58 answers) where strategy video games represented $33.4 \%(n=145)$ of total teachers' choices. Teachers who chose "Other" for the type of video games presented $8.5 \%$ of total participants with 37 choices.

To answer the fourth research question, a one-way ANOVA was used to assess whether there was significant difference between genders. The result of a one-way ANOVA showed there was a statistically significant difference between male and female teachers in the number of hours spent per week on video game play, $F(1,899)=4.03 ;(p<0.04)$. An inspection of the mean scores indicated male teachers reported more hours playing video games, $(M=1.02, S D=1.67)$ than female teachers $(M=0.81, S D=1.41)$.

To answer the fifth research question, a one-way ANOVA was used to assess whether there was a significance difference among levels of teaching (elementary school, middle school, and high school). The result of a one-way ANOVA showed there was no statistically significant difference among elementary, middle, and high school teachers in the number of hours spent per week on video game play: $F(2,898)=1.88$; $(p<$ $0.15)$. Although the mean scores looked very close, high school teachers reported more hours playing video games $(M=1.04$, $S D=1.77)$ than did middle school $(M=0.9, S D=1.4)$ and elementary school $(M=0.8, S D=1.4)$ teachers. To answer the sixth research question, a one-way ANOVA was used to assess whether there was significance difference among teachers' years of experience (1-5, 6-10, 11-15, 16-20 years, and more than 20 years). The results of the Welch ANOVA showed there was a statistically significant difference among teachers' years of experience (1-5, 6-10, 11-15, 16-20, more than 20 years) in the number of hours spent per week on video game play: Welch's $F(4,420.5)=4.12 ;(p<0.003)$. A post hoc analysis was conducted to determine where the differences were within the level of teachers' experience (1-5, 6-10, 11-15, 16-20, more than 20 years). The Games-Howell post hoc analysis indicated a significant difference was between 6-10 years of experience and more than 20 years.

An inspection of the mean scores indicated teachers who had 6-10 years of experience reported highest number of hours playing video games $(M=1.2, S D=1.7)$. Next were teachers who had 11-15 years of experience $(M=0.98, S D=1.8)$, teachers who had 16-20 years of experience $(M=0.85, S D=$ $1.5)$, teachers who had 1-5 years of experience $(M=0.88, S D=$ $1.4)$, and teachers who had more than 20 years of experience $(M=0.61, S D=1.3)$.

To answer the last research question, a one-way ANOVA was used to assess whether there was significance difference among teachers' regions (North, South, West, East, Middle). Although there were different in the mean among teachers' regions East region $(M=2.8)$, North region $(M=2.1)$, South region $(\mathrm{M}=1.6)$, West region $(\mathrm{M}=1.3)$, and Middle region $(\mathrm{M}=1.01)$, The results of the Welch ANOVA showed there was no statistically significant difference among teachers' regions (North, South, West, East, Middle) in the number of hours spent per week on video game play: Welch's $F(4,129.4)=1.9$; $(p<0.14)$.

\section{DISCUSSION AND CONCLUSION}

Based on the results and findings from this section, male teachers represented $48.1 \%$ of the participants and female teachers represented $51.9 \%$ of the participants. The total teacher population in Saudi Arabia was represented by $46 \%$ male teachers and $54 \%$ female teachers. Thus, the ratio between male and female teachers in my sample was comparable to the ratio in the real population. In my sample, $41.4 \%$ of participants were teaching in elementary school, $25.7 \%$ were teaching in middle school, and $32.9 \%$ were teaching in high school. Slightly similar, the population of elementary school teachers in Saudi Arabia is $49.8 \%, 26.4 \%$ for middle school teachers, and $23.8 \%$ for high school.

For the first research question, the findings revealed 53.3\% of total participants did not play video games. This result aligned with prior studies conducted by references [28]-[12]. Reference [28] found $44 \%$ of their sample did not play video games. Another study by reference [12] showed that of 1,628 primary and secondary teachers, $42 \%$ of the teachers never played computer games and 23\% teachers reported they played computer games less than once a month [12]. On the other hand, my results did not support prior studies conducted by reference [38]-[16] where only $15.5 \%$ and $3.2 \%$ of participants, respectively, had never played video games.

By contrast, the results showed $46.7 \%$ of participants played video games. These results were similar to results found in a study by reference [28] where $56.0 \%$ of the respondents played video games. While only about $3 \%$ of my sample played more than eight hours a week, $15 \%$ played the same number of hours in a study conducted by references [17] on pre-service teachers enrolled at a north Texas university. The results from my survey showed that $27.5 \%$ of teachers play video games for one hour a week. My results agreed with findings by reference [12] study, which showed $23 \%$ of the teachers played video games for about one hour a week. Also, the findings of my study showed about $2 \%$ of teachers played video games for more than 10 hours a week. This percentage did not support a prior study by reference [38] whose results showed no teachers played video games more than 10 hours a week.

For In the second research question that about the reasons that attracted Saudi teachers to play video games, the results showed the most popular reason for playing video games among the participants was for enjoyment with $66.8 \%$ of the total answers. This was followed by leisure time--45.1\%, playing video games for intelligence development--42.8\%, playing for competition--37.5\%, playing video games to develop talent--18.9\%, playing games for discovery--16.3\%, and playing for communication--5.7\% of all participants. While $15.2 \%$ of teachers played video games to join others, only $4.8 \%$ of teachers played video games for curiosity. In general, the results showed most of the reasons for playing video games were similar between male and female teachers. The most popular reason for male teachers was competition, while the most reason for playing video games for female teachers was intelligence development.

In the third research question, many types of video games were shown: fighting games, puzzles games, sports games, 
adventure games, strategy games, and other games. The findings revealed $56.9 \%$ of teachers chose puzzle games as their preferred type of video games. Next were sport video games-- $35.1 \%$, strategy video games--33.4\%, adventure video games--28.5\%, and fighting video games--12.7\%. Teachers who chose "Others" for the type of video games represented $8.5 \%$ of the total participants. These results aligned with a prior study in Taiwan when reference [16] found $52.9 \%$ of pre-service teachers preferred puzzle games and about $33.9 \%$ of pre-services teachers preferred sport video games. This comparison among study findings shows that Saudi teachers' gaming preferences are generally aligned with preferences of others documented in the literature.

Regarding the difference between genders, the results revealed male teachers preferred fighting and sport video games while female teachers preferred puzzle, adventure, and strategy games. These results were supported by references [3]-[24]. Although the difference between gender about the type of preferring games is no important for this study, this difference proves the agreement between this study and previous studies. Also, this consideration will help the Ministry of Education in Saudi Arabia for designing the educational video games.

The relationship between the results in question two and three was very interesting. The results showed that the male teachers play video games for competition more than female teachers and in the same time they preferred to play Fighting and Sport games. On the other hand the female teachers play video games for intelligence more than male teachers and in the same time they preferred to play Strategy and Puzzles games. This relationship appeared between the type of video games and reason of playing video games. The competition reason plays main role in Fighting and Sport games and prominent characteristic of these kinds of games. While The intelligence reason plays main supporting role in Strategy and Puzzles games and prominent characteristic of these types of games.

There was a significant difference in the means between male and female teachers in the number of hours games were played $($ males $=1.02$, females $=0.81$ ). This result was expected and complemented the literature because many studies also found similar differences between male and female [2]-[3]-[14]-[27]-[32][35]-[37]. There are many reasons for these differences. The most likely cause of this difference is many games were designed for male players [2]. In addition, reference [24] stated, "One of the arguments that often arises about girls and video games is that girls are not willing to devote as much time to playing as boys" (p.63). Reference [24] also said, "Unfortunately, the current sophistication level of most video games cannot utilize girls' greatest weapons: communication and imagination" (p.64). Finally, reference [35] provided five reasons for this gender discrepancy: "biases against women video game players; preferences of females for more social activities compared to males; less of a need for competitiveness, variety, and accomplishment compared to males; differentiation of play for females versus males; and differences in preferences regarding video game content or goals" (p.26).

Reference [34] explained, Most of the computer games are violent and appeal to the male population; computers are linked to math and science, fields that show an overrepresentation of males; magazines and newspapers depict men using the computer more than women; when women are associated with the computer, it is in a secretarial role; and many teachers encourage boys to use computers but discourage girls from doing so. (p.405)

To implement video games in classroom, students need to be guided through the gaming activities. To do that, teachers need to have some experience about video games to be able to tutor and guide students to use video games in learning [22]. However, having experience with video games is not mandatory. As stated by reference [7], "Teachers don't necessarily need to become experts with every new medium, but at the very least need to know what is going on [...] in order to participate" (p.71). Also, it was said in reference [7] "the description of DGBL is an interplay between distinct but intermingling knowledge aspects, and the need for teachers to become anthropologists rather than gamers" (p.67).

In conclusion, Saudi teachers do not need to be gamers but the Ministry of Education should train them for using the video games before approving the application of their use in classrooms. On the other hand, the difference in teachers' experiences in playing video games between genders does not impact the ability of applying video games in classrooms. Many previous works and this study results proved that male play video games more than female.

\section{REFERENCES}

[1] Al-Hadlaq, A. A. (2011). The advantages and disadvantages of playing electronic games and motives of the playing from the viewpoints of public education students in Riyadh City. Riyadh: King Saud University.

[2] Aliefendic, J. (2013). The correlation between the time spent playing educational video games and students' performance on standardized mathematics tests by fifth-grade students (Doctoral dissertation). Retrieved from http://dmc.tamuc.edu/ cdm/ref/ collection/p15778coll7/id/80/.

[3] Alqurashi, M., Almoslamani, Y. \& Alqahtani, A. (2015, June). Middle school students' digital game experiences in Makkah in Saudi Arabia. Proceedings from the Second International Conference on Education, Social Sciences and Humanities, Istanbul, Turkey.

[4] Alshammary, G. (2014). Electronic games!! Retrieved from http://www.alyaum.com/ article/4030423

[5] Amory, A., Naicker, K., Vincent, J. \& Adams, C. (1998). Computer games as a learning resource. Retrieved from http://www.editlib.org/j/EDMEDIA/

[6] Beck, J. C., \& Wade, M. (2004). Got game: How the gamer generation is re-shaping business forever. Boston, MA: Harvard Business School Press.

[7] Bourgonjon, J., \& Hanghøj, T. (2011). What does it mean to be a game literate teacher? Interviews with teachers who translate games into educational practice. Paper presented at the 5th European Conference on Games-Based Learning (ECGBL'11), Athens, Greece.

[8] Clark, A. C., \& Ernst, J. V. (2009). Gaming in technology education. Technology Teacher, 68(5), 21-26.

[9] Communications and Information Technology Commission. (2014). $\begin{array}{llll}\text { Annual report. } & \text { Retrieved }\end{array}$ http://www.citc.gov.sa/arabic/MediaCenter/Annualreport/ Documents/PR_REP_010A.pdf

[10] Del-Moral Pérez, M. (2014). Videogames: Opportunities for learning. Journal of New Approaches In Educational Research, 3(1), 1.

[11] Entertainment Software Association. (2015). Improving what matters. Retrieved from http://www.theesa.com 
[12] FutureLab. (2009). Using computer games in the classroom. Retrieved from http://www.futurelab.org.uk/resources/documents/project_ reports/becta/ Games_and_Learning_survey_analysis.pdf Gibson

[13] Hayes, E., \& Ohrnberger, M. (2013). The gamer generation teaches school: The gaming practices and attitudes towards technology of pre-service teachers. Journal of Technology and Teacher Education, 21(2), 154-177.

[14] Hofferth, S. L. (2010). Home media and children's achievement and behavior. Child Development, 81(5), 1598-1619.

[15] Howard, C., Morgan, M., \& Ellis, K. (2006). Games and learning ... Does this compute? In E. Pearson \& P. Bohman (Eds.), Proceedings of World Conference on Educational Media and Technology 2006 (pp. 1217-1224). Waynesville, NC: Association for the Advancement of Computing in Education.

[16] Hsu, T. Y., \& Chiou, G. F. (2011). Preservice science teachers' prior game play experience and their perceptions of digital game-supported learning. $\quad$ Retrieved from https://www.researchgate.net/publication/268347194_Preservice_ Teachers'_Awareness_of_Digital_Game-Supported_Learning

[17] Jones, J. G., Copeland, B., \& Kalinowski, K. (2007). Pre-service teacher's attitudes towards computer games. Paper presented at the American Educational Research Association, Chicago, IL.

[18] Kirriemuir, J., \& McFarlane, A. (2004). Literature review in games and learning: A NESTA Futurelab research report. Retrieved from http://www2.futurelab.org.uk/ documents/lit_reviews/Games_Review.pdf

[19] Malone, T. (1980). What makes things fun to learn? A study of intrinsically motivating computer games. Palo Alto, CA: Xerox.

[20] Malone, T. (1981). Toward a theory of intrinsically motivating instruction. Cognitive Science, 5(4), 333-369.

[21] Marín Díaz, V. \& Martín-Párraga, J. (2014). Can videogames be used to develop the infant stage educational curriculum? Journal of New Approaches In Educational Research, 3(1), 20-25.

[22] Marklund, B. B., \& Taylor, A. S. A. (2015, October). Teachers' Many Roles in Game-Based Learning Projects. In European Conference on Games Based Learning (p. 359). Academic Conferences International Limited.

[23] McFarlane, A., Sparrowhawk, A., \& Heald, Y. (2002). Report on the educational use of games: An exploration by TEEM of the contribution which games can make to the education process. Retrieved from http://www.diversaodigital.com/ educacao/teem_gamesined_full.pdf

[24] Miller, C. T. (2008). Games: Purpose and potential in education. New York: Springer.

[25] Ministry of Education in Saudi Arabia. (2014, March 13). Statistical reports [Data file]. Retrieved from https://www.moe.gov.sa/Arabic/Ministry /Pages/Statistical-reports.aspx

[26] Museum of Play. (2015). Video game history timeline. Retrieved from http://www.museum ofplay.org/icheg-game-history/timeline/

[27] Nippold, M. M. A., Duthie, J. K., \& Larsen, J. (2005). Literacy as a leisure activity: Free-time preferences of older children and young adolescents. Language, Speech, and Hearing Services in Schools, 36(2), 93-102.

[28] Noraddin, E. M., \& Kian, N. T. (2014). Academics' attitudes toward using digital games for learning \& teaching in Malaysia. Malaysian Online Journal of Educational Technology, 2(4).

[29] Ortega, M. (2012). Technology in the educational setting past present and future. Proceedings of Society for Information Technology \& Teacher Education International Conference 2012, Chesapeake, VA.

[30] Pimenta Arruda, E., \& Pimenta Arruda, D. (2014). Leisure, digital games and learning: Perspectives for school education. International Journal on E-Learning, 13(4), 467-482.

[31] Quaiser-Pohl, C., Geiser, C., \& Lehmann, W. (2006). The relationship between computer-game preference, gender, and mental-rotation ability. Personality and Individual Differences, 40(3), 609-619.

[32] Qudair, M. (2011). The impact of electronic games on children behavior. Unpublished master thesis, Algiers University, Algeria.

[33] Roberts, N. (1976). Simulation gaming: A critical review. Retrieved from http://files.eric.ed.gov /fulltext/ED137165.pdf.

[34] Sharp, V. (2005). Computer education for teachers: Integrating technology into classroom teaching $\left(5^{\text {th }}\right.$ ed). New York: McGraw-Hill Companies, Inc.

[35] Tobias, S., Halter, J., \& Newbauer, D. (2015). Relationships between video game play and family environment among female university student game players living at home. Retrieved from https://www.highbeam.com/doc/1P3-3700216921.html

[36] Video game. (2016). In Oxford English Dictionary online. Retrieved from http://www.oxford dictionaries.com/definition/english/video-game?q=video+game
[37] Winn, J., \& Heeter, C. (2009). Gaming, gender, and time: Who makes time to play? Sex Roles, 61(1-2), 1-13. doi:10.1007/s11199-009-9595-7

[38] Wu, M. L. (2015). Teachers' experience, attitudes, self-efficacy and perceived barriers to the use of digital game-based learning: A survey study through the lens of a typology of educational digital games. Retrieved from http://gradworks.umi.com/ 37/14/3714969.html 